\title{
Diagnostic value of blood cytokine concentrations in acute pneumonia
}

Department of Infectious Diseases

P Kragsbjerg

$\mathrm{T}$ Vikerfors

H Holmberg

Department of Clinical Chemistry I Jones

Örebro Medical Center Hospital, S-701 85 Örebro, Sweden

Reprint requests to: Dr P Kragsbjerg.

Received 14 March 1995 Returned to authors 5 June 1995

Revised version received 14 August 1995

Accepted for publication

4 September 1995

\author{
Peter Kragsbjerg, Ian Jones, Tomas Vikerfors, Hans Holmberg
}

\begin{abstract}
Background - The role of cytokines in the pathogenesis of pneumonia is still poorly understood. In a previous study the diagnostic value of measuring blood concentrations of interleukin 6 and interferon $\gamma$ was established. In the present study the value of blood concentrations of interleukin 8, granulocyte-colony stimulating factor, and lactoferrin as markers of bacteraemic pneumonia is evaluated.

Methods - The circulating concentrations of interleukin 8 (IL-8), granulocyte-colony stimulating factor (G-CSF), and lactoferrin were measured in 14 patients with bacteraemic pneumococcal pneumonia and 49 patients with atypical pneumonia or influenza $A$ infection using enzyme immunoassays.
\end{abstract}

Results - Serum G-CSF concentrations were higher in the group with bacteraemic pneumococcal pneumonia, and G-CSF values correlated with the white blood cell count and levels of $\mathrm{C}$-reactive protein (CRP). The levels of IL-8 were higher in the group with bacteraemic pneumococcal pneumonia than the groups with Chlamydia pneumonia, Legionella pneumonia, or influenza $A$ infection, but there was no difference when compared with the group with Mycoplasma pneumonia. A white blood cell count of $>15 \times 10^{9} / 1$ was highly suggestive of bacteraemic pneumonia. The concentrations of lactoferrin were raised in all groups except those with influenza $A$ infection, but no difference was found between the different aetiological groups. A correlation was found between lactoferrin and white blood cell counts.

Conclusions - Serum G-CSF and IL-8 concentrations are potential markers of bacteraemic pneumonia.

(Thorax 1995;50:1253-1257)

Keywords: diagnosis, cytokines, pneumonia.

Neutrophils play a major part in the immune defence against infection by eliminating pathogens through phagocytosis and intracellular killing using oxidative and non-oxidative pathways. ${ }^{1}$ Killing by the non-oxidative pathway involves release of enzymes and other substances from primary or secondary granules. Lactoferrin is a glycoprotein contained in secondary granules, it is released during neutrophil antibacterial activity, and raised circulating concentrations have been found in patients with sepsis. ${ }^{2}$ Interleukin 1 (IL-1), tumour necrosis factor $\alpha(\mathrm{TNF}-\alpha)$, and granulocyte-colony stimulating factor (G-CSF) are some of the cytokines that regulate neutrophil activity in severe bacterial infections, ${ }^{3}$ and all three cytokines, which are produced mainly by monocytes/macrophages, have been shown to enhance neutrophil antibacterial activity. ${ }^{4}$ IL1 and TNF- $\alpha$ also induce the production of other cytokines which have regulatory functions - for example, interleukin-8 (IL-8) - which also enhance neutrophil function. ${ }^{5}$

The role of IL-8 in the adult respiratory distress syndrome (ARDS) and bacterial pneumonia has recently been investigated in a study of 18 patients. ${ }^{6}$ Raised levels of IL- 8 in bronchoalveolar lavage (BAL) fluid were related to a poor prognosis, whereas circulating IL-8 levels were increased in all patients and no significant correlation with outcome was found.

The present study was conducted to investigate the significance of serum concentrations of IL-8, G-CSF, and lactoferrin in patients with aetiologically well defined pneumonia or influenza A infection. The aim was to evaluate a possible clinical application of serum levels of IL-8, G-CSF, and lactoferrin as markers of bacterial infection, and to correlate the levels of these inflammatory mediators with the clinical presentation and routine laboratory parameters of the patients.

\section{Methods}

Sixty three patients with acute respiratory tract infections admitted to the Department of Infectious Diseases, Örebro Medical Center Hospital (ÖMCH) were included retrospectively. There were 14 patients with bacteraemic pneumococcal pneumonia, 12 with clinical and serologically proven pneumonia due to Chlamydia species, six with Legionella pneumonia, 14 with pneumonia due to Mycoplasma pneumoniae, and 17 with influenza A virus infection.

Diagnostic criteria for bacteraemic pneumococcal pneumonia were an acute clinical pneumonia and growth of Streptococcus pneumoniae in one or more blood cultures (Bactec $660 \mathrm{HP}$, Becton Dickinson, USA). Diagnostic criteria for verification of an atypical or viral aetiology were either a four fold or greater increase in antibody titres in serum samples from acute and convalescent patients or a single titre of $\geqslant 1 / 40$ for Chlamydia, $\geqslant 1 / 160$ for Mycoplasma pneumoniae, and $\geqslant 1 / 256$ for Legionella infections. Complement fixation or indirect immunofluorescence tests were used for the diagnosis of Chlamydia, Mycoplasma, influenza A virus, or Legionella infection. Antigen de- 
Table 1 Median age (range), sex distribution, time from onset of disease to admission (delay), and number of patients who had received an appropriate antibiotic before admission in 63 patients with pneumonia or influenza $A$ virus infection

\begin{tabular}{|c|c|c|c|c|c|}
\hline Aetiology & $n$ & $\begin{array}{l}\text { Age } \\
\text { (years) }\end{array}$ & $\begin{array}{l}\text { Sex } \\
(F / M)\end{array}$ & $\begin{array}{l}\text { Delay } \\
\text { (days) }\end{array}$ & $\begin{array}{l}\text { Antiobiotic before } \\
\text { admission }\end{array}$ \\
\hline$S$ pneumoniae & 14 & $\begin{array}{l}68 \\
(20-83)\end{array}$ & $7 / 7$ & \multirow{5}{*}{$\begin{array}{l}2 \\
(1-5) \\
6 \\
(1-14) \\
5 \\
(3-43) \\
7 \\
(3-14) \\
1 \\
(1-7)\end{array}$} & $0 / 14$ \\
\hline Chlamydia spp & $12^{\mathrm{a}}$ & $\begin{array}{l}64 \\
(21-83)\end{array}$ & $4 / 8$ & & $1^{b} / 12$ \\
\hline Legionella spp & 6 & $\begin{array}{l}57 \\
(31-79)\end{array}$ & $4 / 2$ & & $1 \%$ \\
\hline$M$ pneumoniae & 14 & $\begin{array}{l}35 \\
(9-88)\end{array}$ & $9 / 5$ & & $2^{\mathrm{d}} / 14$ \\
\hline Influenza $\mathrm{A}$ virus & 17 & $\begin{array}{l}77 \\
(54-92)\end{array}$ & $13 / 4$ & & $0 / 17^{\mathrm{e}}$ \\
\hline
\end{tabular}

ane double infection with influenza $A$ virus.

$200 \mathrm{mg}$ doxycycline on the day of admission.

'The patient with the delay of 43 days was treated at another hospital with several antibiotics, the latest being doxycycline $100 \mathrm{mg}$ twice daily.

Few days of $500 \mathrm{mg}$ erythromycin twice daily.

One patient had received norfloxacin for cystitis, no other patient had received antibiotic treatment before admission.

tection by immunofluorescence on nasopharyngeal specimens and/or a complement fixation test on serum samples were used for the diagnosis of influenza $\mathrm{A}$ infection.

In the patients with atypical pneumonia or influenza A infection routine cultures were carried out. Among the 49 patients 46 nasopharynx cultures were performed, sputum cultures were done in nine, and blood cultures were grown in 33; all were negative.

The diagnosis of pneumonia was verified with a chest radiograph in the cases with atypical pneumonia and pneumococcal pneumonia, except one patient who had typical clinical signs of pneumonia in the right lung but a negative radiograph on admission. In the patients with influenza $A$ infection 12 out of 17 had radiography performed and all were negative. In the other five patients with influenza $A$ virus infection there were no clinical signs of pneumonia and radiography was not performed.

The age and sex distribution, delay and frequency of appropriate antibiotic therapy before admission are shown in table 1. Eleven of the 14 patients with bacteraemic pneumococcal pneumonia had chronic or predisposing diseases on admission. The frequency of present chronic or predisposing disease in the other groups was four of 12 with Chlamydia pneumonia, five of six with Legionella pneumonia, one of 14 with Mycoplasma pneumonia, and 15 of 17 with influenza $A$ virus infection.

Serum samples were collected on admission to hospital in 58 of the 63 patients or early during the hospital stay in the remaining five, in association with an acute respiratory tract infection. In some cases a convalescent sample was obtained 2-8 weeks after the acute episode. The serum samples were stored at $-20^{\circ} \mathrm{C}$ until analyses were performed at the Departments of Clinical Immunology and Clinical Chemistry, ÖMCH, using commercially available enzyme immuno assays (IL-8 and G-CSF Quantikine, R \& D Systems Europe, UK) or an in-house ELISA for lactoferrin as described below.

CYTOKINE ANALYSIS

The serum samples were tested undiluted once and then for G-CSF diluted 1:10, setting the upper detection limit at $50000 \mathrm{pg} / \mathrm{ml}$. The serum was diluted 1:2 when measuring IL-8 in samples from the patients with bacteraemic pneumococcal pneumonia. The performance of the kits was evaluated using human recombinant cytokines obtained from the National Institute of Biological Standardisation and Control, Potters Bar, UK (IL-8, 89/520; G-CSF, 88/502), R \& D Systems Europe, UK (IL-8, BDP 44), and Boehringer Mannheim, BRD (G-CSF, 1296 752). The ELISA detected the recombinant cytokines in a dose-dependent manner and the recovery rates were constant.

\section{LACTOFERRIN ANALYSIS}

Polystyrene microplates (MaxiSorp, Nunc, Roskilde, Denmark) were coated overnight with sheep antihuman lactoferrin (The Binding Site, Birmingham, UK) in a $0.05 \mathrm{~mol} / 1$ $\mathrm{NaHCO}_{3}$ buffer, $\mathrm{pH} 9 \cdot 5$. The antibody concentration was $12 \mathrm{mg}$ protein/l. The wells were then washed five times with a washing solution ${ }^{7}$ using a Delfia platewash (Wallac, Turku, Finland). A seven point standard curve from $2 \cdot 0 \mu \mathrm{g} / 1$ to $100 \mu \mathrm{g} / \mathrm{l}$ was constructed based upon human lactoferrin (L3770, Sigma, St Louis, USA). The serum samples were diluted 1:60 in most cases, 1:100 and 1:200 dilutions being used for the few high samples. The patient samples and the standard curve were diluted in a buffer described by Antonsen et al. ${ }^{8} 100 \mu \mathrm{l}$ of samples and standards were pipetted into the wells in duplicate and the plate was incubated for 60 minutes. The plate was then washed four times as described above before the second incubation of 60 minutes with a horseradish peroxidase labelled sheep antihuman lactoferrin (The Binding Site, Birmingham, UK). The antibody was diluted in the wash solution to a concentration of $5 \mathrm{mg}$ protein/l. After the incubation the plate was washed a further four times before the substrate incubation step. The substrate consisted of freshly prepared orthophenylenediamine (OPD tablets, Dakopatts A/S, Copenhagen, Denmark) dissolved in $0.1 \mathrm{~mol} / 1$ citrate phosphate buffer, $\mathrm{pH} \quad 5.0 \quad(12 \mathrm{mg} \quad \mathrm{OPD}+18 \mathrm{ml}$ buffer $+8 \mu 130 \%$ hydrogen peroxide). The incubation time was 5-10 minutes and the absorbance was read at $490 \mathrm{~nm}$ after the reaction was stopped with $1 \mathrm{~mol} / 1$ sulphuric acid. The recovery of serum sample spiked with $1 \mathrm{mg} /$ 1 was $85 \%$. The within and between series imprecision was $6.9 \% \quad(n=15)$ and $8 \cdot 7 \%$ $(\mathrm{n}=11)$, respectively, at a level of $1.9 \mathrm{mg} / 1$. CRP was detected using an immunoturbidometric method in routine use (BM/Hitachi 704, Boehringer Mannheim $\mathrm{GmbH}$, Germany). White blood cell count was determined using routine methods.

Serum samples from 20 blood donors were used as controls. The patients' files were reviewed for clinical information. The study was approved by the local ethics committee.

STATISTICAL METHODS

As the values were not normally distributed, differences between the groups were estimated using the Kruskal-Wallis and Mann-Whitney 
$\mathrm{U}$ tests, and correlations were evaluated by the Spearman rank correlation coefficient. The Statview 4.01 (Abacus Concepts, Berkeley, USA) statistical software was used for the calculations.

\section{Results}

PATIENTS

The patients with pneumonia caused by $\mathrm{Myco}$ plasma were significantly younger than the other patients. The groups with infections caused by bacteraemic pneumococcal pneumonia and influenza $A$ virus had a significantly shorter time from onset of disease to admission to hospital than the other groups. A significant correlation was found between acute concentrations of G-CSF and maximum white blood cell count $(r=0.36, \mathrm{p}=0.01)$, between G-CSF and CRP $(r=0.48, \mathrm{p}<0.001)$, and between lactoferrin and white blood cell counts on admission $(r=0.29, \mathrm{p}<0.05)$. Otherwise there were no significant correlations between levels of IL-8, G-CSF, lactoferrin, white blood cells, or CRP. Body temperature on admission and IL-8, G-CSF, lactoferrin, white blood cell, or CRP concentrations did not correlate. There was no correlation between age or delay and levels of IL-8, G-CSF, lactoferrin, white blood cells, or CRP. The mortality rate in the study was $1.6 \%$ (one of 63 ).

\section{ANALYSIS OF SERUM SAMPLES \\ IL-8}

The serum IL-8 concentrations were significantly higher among the patients with bacteraemic pneumococcal pneumonia than in patients with Chlamydia pneumonia ( $\mathrm{p}=$ $0.005)$, Legionella pneumonia $(\mathrm{p}=0.01)$, or influenza A virus infection $(\mathrm{p}<0 \cdot 05)$. The distribution of values in the different aetiological groups is shown in fig $1 \mathrm{~A}$.

\section{G-CSF}

The serum G-CSF concentrations were significantly higher in the group of patients with bacteraemic pneumococcal pneumonia than in all other groups $(p<0.0005)$ as shown in fig $1 B$.

\section{Lactoferrin}

The patients with pneumonia had significantly higher levels of lactoferrin than the control group $(p<0.05)$, irrespective of the causative organism. There were no significant differences between the aetiological groups (fig 1C).

White blood cell counts

There was a significant difference in the levels on admission between the patients with bacteraemic pneumococcal pneumonia and those with Chlamydia pneumonia, Mycoplasma pneumonia, and influenza $A$ virus infection $(p<0.005)$. When the maximum values during the hospital stay were used for analysis the patients with bacteraemic pneumococcal pneu-
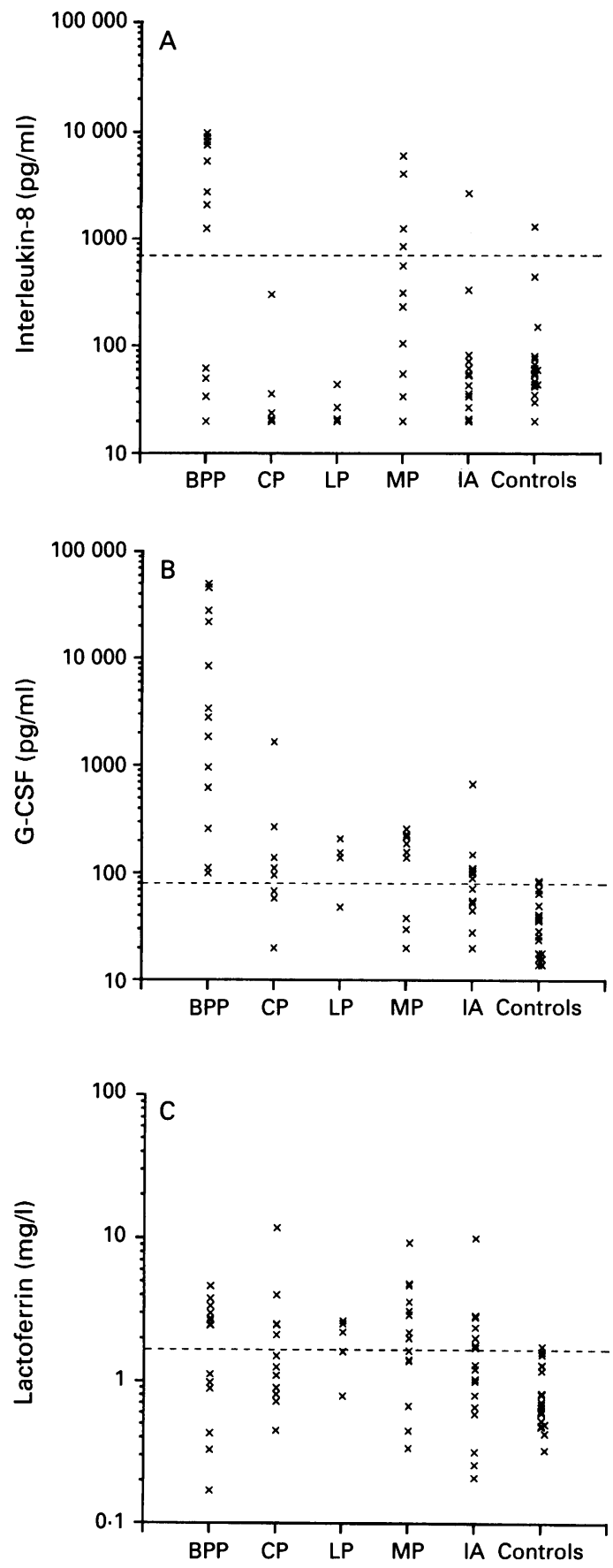

Figure 1 Distribution of serum concentrations of $(A)$

$I L-8,(B) G-C S F$, and (C) lactoferrin in 63 patients with bacteraemic pneumococcal pneumonia (BPP), Chlamydia pneumonia (CP), Legionella pneumonia ( $L P)$,

Mycoplasma pneumonia (MP), influenza $A$ infection (IA), and in 20 blood donors (controls). Horizontal lines indicate the upper reference limit.

monia had significantly higher white blood cell counts than patients with Chlamydia pneumonia, Mycoplasma pneumonia and influenza A virus infection $(\mathrm{p}<0.0005)$ and also Legionella pneumonia $(\mathrm{p}<0.05)$. The values for individual groups are shown in fig $2 \mathrm{~A}$.

\section{$C R P$}

Serum concentrations of CRP were significantly higher among patients with bacteraemic pneumococcal pneumonia than those with influenza A virus infection $(\mathrm{p}<0.005)$ and Mycoplasma pneumonia $(\mathrm{p}<0 \cdot 05)$. All aetio- 

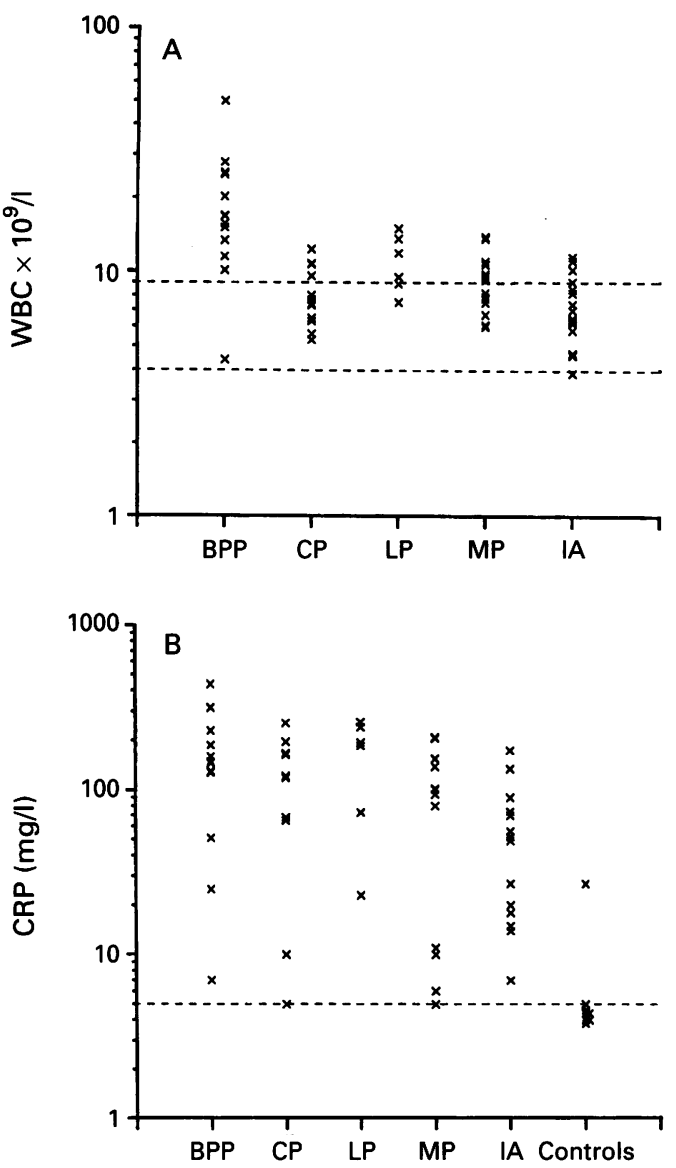

Figure 2 Distribution of (A) maximum blood white blood cells (WBC) and (B) serum $C$ reactive protein $(C R P)$ on admission in 63 patients with bacteraemic pneumococcal pneumonia (BPP), Chlamydia pneumonia (CP), Legionella pneumonia (LP), Mycoplasma pneumonia (MP), influenza $A$ infection (IA), and in 20 blood donors (controls). Horizontal lines indicate the normal reference range for white blood cells and the upper reference limit for CRP.

logical groups had levels higher than the control group, but the differences between the other aetiological groups were not significant (fig $2 \mathrm{~B}$ ).

The sensitivity, specificity, predictive value of a positive and negative test for IL-8, G$\mathrm{CSF}$, lactoferrin, CRP, and white blood cells to indicate a bacteraemic pneumonia are shown in table 2.

\section{CONTROLS}

The mean (SD) serum concentration of IL-8 was 139 (287) $\mathrm{pg} / \mathrm{ml}, \mathrm{G}-\mathrm{CSF}$ was 37 (22) pg/ $\mathrm{ml}$, lactoferrin was $0.86(0.43) \mathrm{mg} / \mathrm{l}$, and CRP was $6(5) \mathrm{mg} / \mathrm{l}$. The upper reference limits for these four parameters were taken as the mean

Table 2 Diagnostic value of blood concentrations of IL-8, G-CSF, lactoferrin, CRP, and white blood cell counts to indicate a bacteraemic pneumonia

\begin{tabular}{lllll}
\hline & Sensitivity & Specificity & $\begin{array}{l}\text { Predictive } \\
\text { value of positive test }\end{array}$ & $\begin{array}{l}\text { Predictive } \\
\text { value of negative test }\end{array}$ \\
\hline $\begin{array}{llll}\text { IL-8 } \\
\text { (cut off } 400 \mathrm{pg} / \mathrm{ml} \text { ) }\end{array}$ & 0.57 & 0.86 & 0.57 & 0.86 \\
$\begin{array}{l}\text { G-CSF } \\
\text { (cut off } 400 \mathrm{pg} / \mathrm{ml} \text { ) }\end{array}$ & 0.76 & 0.95 & 0.83 & 0.93 \\
$\begin{array}{l}\text { Lactoferrin } \\
\text { (cut off } 2.0 \mathrm{mg} / \mathrm{l} \text { ) }\end{array}$ & 0.54 & 0.57 & 0.25 & 0.82 \\
CRP & 0.79 & 0.60 & 0.37 & 0.93 \\
$\begin{array}{l}\text { (cut off } 100 \mathrm{mg} / \mathrm{l} \text { ) } \\
\text { WBC }\end{array}$ & 0.71 & 0.97 & 0.90 & 0.90 \\
(cut off $15 \times 10^{9} / \mathrm{l}$ ) & & & &
\end{tabular}

$+2 S D$. The reference range for white blood cell counts was $4-9 \times 10^{9} / 1$.

\section{Discussion}

In this study we have investigated the serum concentrations of the cytokines, IL-8 and GCSF, and a neutrophil secondary granule glycoprotein, lactoferrin, in patients with pneumonia or influenza A virus infection, and compared the values with routinely used parameters such as white blood cell count and CRP. Serum G-CSF concentrations were significantly higher among the patients with bacteraemic pneumococcal pneumonia than those with atypical pneumonia or influenza $A$ infection. G-CSF also correlated with the maximum white blood cell count and CRP on admission, a finding in agreement with a previous study. ${ }^{9}$ In the present study a serum concentration of G-CSF above $400 \mathrm{pg} / \mathrm{ml}$ was highly suggestive for bacteraemic pneumonia.

The serum concentrations of IL-8 were also significantly higher among patients with bacteraemic pneumococcal pneumonia than among those with pneumonia caused by Chlamydia, Legionella, and influenza A virus, but not different from the concentrations found in the patients with infection caused by $\mathrm{Myco}-$ plasma. Although we found significant differences between different aetiologically defined groups, the measurement of IL-8 in blood is associated with difficulties, a recent report showing that erythrocytes bind IL-8. ${ }^{10}$ Variable binding of IL-8 may thus account for variations in the serum or plasma concentrations measured.

The serum concentrations of lactoferrin did not discriminate between bacteraemic pneumococcal pneumonia and atypical pneumonia or influenza $A$ virus infection and a similar lack of diagnostic potential was also found in a previous study on meningococcal septicaemia in children. ${ }^{11}$ In a study of patients with sepsis, plasma lactoferrin concentrations correlated with plasma elastase $/ \alpha_{1}$-antitrypsin complex levels and leucocyte counts, ${ }^{2}$ and in the present study of patients with acute pneumonia serum lactoferrin levels also correlated with leucocyte counts on admission.

The leucocytosis commonly associated with pneumococcal pneumonia was found among the 14 patients in this study but the levels were significantly higher only when compared with the patients with influenza A virus infection. However, when the maximum values during the hospital stay were used for analysis the patients with bacteraemic pneumococcal pneumonia had significantly higher white blood cell counts than patients with pneumonia caused by Chlamydia, Mycoplasma, and influenza A virus. The use of the white blood cell count to discriminate between pneumococcal pneumonia and viral or atypical pneumonia has been investigated previously and found to be of benefit when used in association with other parameters such as age and serum lactate dehydrogenase levels. ${ }^{12}$ In the present study a white blood cell count of $>15 \times 10^{9} / 1$ was highly suggestive of bacteraemic pneumococcal pneu- 
monia and its diagnostic value approaches that of G-CSF.

The patients with Mycoplasma pneumonia were younger than the other groups, but this difference was not associated with differences in cytokine levels. The patients with atypical pneumonia had longer delays than had the patients with bacteraemic pneumococcal pneumonia or influenza A virus infection, making it possible that acute high levels of cytokines may have decreased by the time the patients were admitted. However, the delay reflects the clinical situation and all patients were admitted to the infectious disease ward because of the severity of their condition. Futhermore, none of the patients was in shock on admission and there were no differences in body temperature.

The circulating levels of cytokines decrease rapidly after effective antibiotic therapy, ${ }^{13}$ and treatment with appropriate antibiotics before admission might thus influence the cytokine concentrations measured on admission. In the present study only four of the 63 patients had received an effective antibiotic before admission to hospital.

In summary, patients with bacteraemic pneumococcal pneumonia had significantly higher circulating levels of G-CSF and IL-8 on admission than patients with atypical pneumonia or influenza A infection, and acute analysis of these two cytokines might thus be useful as markers of bacteraemic pneumonia. A high white blood cell count was also found to be suggestive for bacteraemic pneumonia. Analysis of serum lactoferrin and CRP showed less discriminatory ability.
The authors thank Ms Margaretha Jurstrand for expert technical assistance and the Örebro County Council Research Unit for financial support.

1 Cohen MS. Molecular events in the activation of human neutrophils for microbial killing. Clin Infect Dis 1994;18: S170-9.

2 Nuijens JH, Abbink JJ, Wachtfogel YT, Colman RW, Eerenberg AJM, Dors D, et al. Plasma elastase $\alpha_{1}$-antitrypsin and lactoferrin in sepsis: evidence for neutrophils as mediators in fatal sepsis. F Lab Clin Med 1992;119. 159-68.

3 Nelson S. Role of granulocyte colony-stimulating factor in the immune response to acute bacterial infection in the non-neutropenic host: an overview. Clin Infect Dis 1994; 18:S197-204.

4 Steinbeck MK, Roth JA. Neutrophil activation by recombinant cytokines. Rev Infect Dis 1989;11:549-68.

5 Djeu JY, Matsushima K, Oppenheim JJ, Shiotsuki K, Blanchard DK. Functional activation of human neutrophils by recombinant monocyte-derived neutrophil chemotactic factor/IL-8. F Immunol 1990;144:2205-10.

6 Chollet-Martin S, Montravers P, Gibert C, Elbim C, Desmonts JM, Fagon JY, et al. High levels of interleukin- 8 in the blood and alveolar spaces of patients with pneumonia and adult respiratory distress syndrome. Infect Immun 1993;61:4553-9.

7 Gutteberg TJ, Slørdal L, Kolmannskog S. Lactoferrin and C-reactive protein in response to cytostatic drugs with emphasis on methotrexate. Pediatr Hematol Oncol 1987;4: 315-22.

8 Antonsen S, Wiggers P, Dalhøj J, Blaabjerg O. An enzymelinked immunosorbent assay for plasma-lactoferrin. Concentrations in 362 healthy, adult blood donors. Scand $\mathcal{Y}$ Clin Lab Invest 1993;53:133-44.

9 Pauksen K, Elfman L, Ulfgren A-K, Venge P. Serum levels of granulocyte-colony stimulating factor in bacterial and viral infections, and in atypical pneumonia. $B r F$ Haematol 1994;88:256-60.

10 Darbonne WC, Rice GC, Mohler MA, Apple T, Hébert CA, Valente AJ, et al. Red blood cells are a sink for interleukin 8, a leukocyte chemotaxin. $\mathcal{F}$ Clin Invest 1991; interleukin 8,

11 Gutteberg TJ, Haneberg B, Jørgensen T. The latency of serum acute phase proteins in meningococcal septicemia with special emphasis on lactoferrin. Clin Chim Acta 1984 146:173-8.

12 Holmberg H, Bodin L, Jönsson I, Krook A. Rapid aetiological diagnosis of pneumonia based on routine laboratory features. Scand f Infect Dis 1990;22:537-45.

13 Söderquist B, Sundqvist KG, Vikerfors T. Kinetics of serum levels of interleukin-6 in Staphylococcus aureus septicemia. Scand $\mathcal{F}$ Infect Dis 1992;24:607-12. 